\title{
CORRIGENDUM
}

\section{Potential of immunomodulatory agents for prevention and treatment of neonatal sepsis}

\section{JL Wynn, J Neu, LL Moldawer and 0 Levy}

Journal of Perinatology (2009) 29, 527; doi:10.1038/jp.2009.48

Correction to: Journal of Perinatology (2009) 29, 79-88. doi:10.1038/jp.2008.132

The agonist for TLR3 should read dsRNA instead of ds DNA. Please see revised figure given below.

Since the publication of the above paper, the authors have identified the following error in Figure 2:

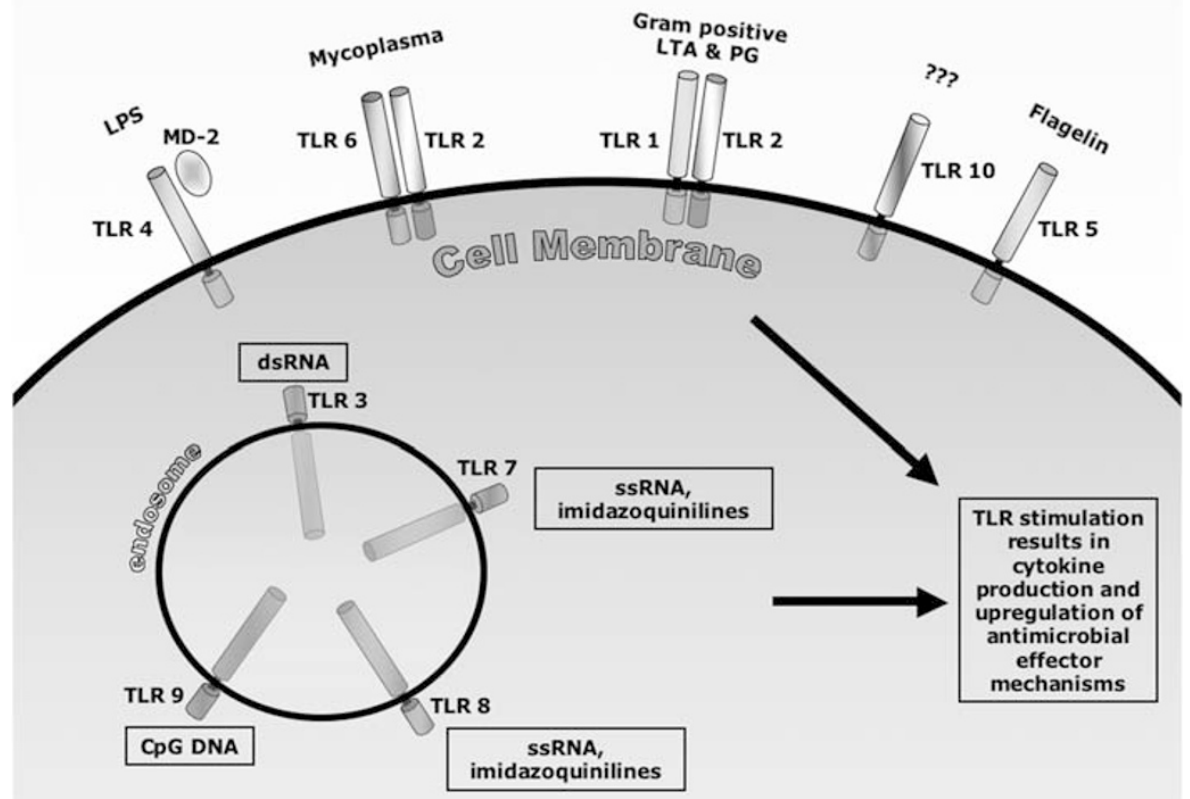

